\title{
Preoperative Relaxation Techniques for Breast Cancer Patients Undergoing Breast-Altering Surgery: A Systematic Review
}

\author{
Hallie Evans*, Ellen L Brown and Jeffrey Groom \\ Clinical Assistant Professor, Florida International University, USA
}

*Corresponding author: Hallie Evans, Clinical Assistant Professor, Florida International University, USA.

Received Date: February 14, 2019

Published Date: March 19, 2019

\begin{abstract}
Context: Preoperative relaxation techniques and complementary alternative treatments being used with breast cancer patients undergoing breast-altering surgery.

Objective: To examine the effectiveness of preoperative relaxation techniques to decrease anxiety in breast cancer patients undergoing breast-altering surgery.

Data Sources: A systematic review of English articles used the PubMed, Embase, and CINAHL databases. Searching bibliographies identified additional studies.

Study selection: Six interventional research studies met the criteria for this specific patient population. Inclusion criteria included interventional studies within the last 10 years written in English, women 18 years old and over, either diagnosed or suspected breast cancer undergoing breast-altering surgery. Implementation strategies including music therapy, stress management training, informational and emotional support sessions, an informational video, and hypnosis were examined.
\end{abstract}

Results: The 6intervention studies reviewed included 462 women, ages 18 and older. Effective intervention employed to reduce anxiety symptoms among preoperative breast cancer patients included informational and emotional support programs, music, and hypnosis. Stress-management training and videotaped information did not result in a significant decrease in anxiety symptoms.

Conclusion: There is scant research to draw on to determine the optimal approach to decrease preoperative anxiety for this patient population. Four of the 6 studies examined reported a decrease in anxiety; however, the interventions and measurement of anxiety symptoms varied across studies. More research is needed to study the effects of relaxation techniques and the best time to incorporate these techniques for breast cancer patients undergoing breast-altering operative procedures.

Keywords: Preoperative; Relaxation technique; Complementary alternative therapy; Complementary alternative medicine; Breast cancer; Surgery

Abbreviations: M:Mean; N; Total Sample Size; n: Sub-Sample Size; ASA: American Society of Anesthesiologists ; COPD: Chronic Obstructive Pulmonary Disease; SSAS: State Anxiety Scale; VAS: Visual Analog Scale; PACU: Post-anesthesia Care Unit; CMSAS-M: Condensed Memorial Symptom Assessment Scale- Modified; POMS: Profile of Mood States; DI: Demographic Inventory; BIS: Body Image Scale ; A-VAS: Anxiety-Visual Analog Scale, T1, T2, T3: Time 1, Time 2, Time 3

\section{Introduction}

Preoperative anxiety is an issue that affects surgical patients, at a higher incidence in certain patient populations such as breast cancer patients. Complementary alternative treatments are techniques that can be used in conjunction with pharmacological treatments to help reduce preoperative anxiety in breast cancer patients undergoing breast-altering surgery including biopsies, lumpectomies, partial mastectomy, complete mastectomy, and bilateral mastectomies. The purpose of this systematic review is to examine the current research on complementary alternative 
treatments used to decrease preoperative anxiety in breast cancer patients undergoing breast-altering surgery. "Anxiety can be defined as feelings of tension, apprehension, nervousness, fear and high autonomic activity that varies in intensity and degree of fluctuation over time." [1] (Studies have reported the immediate preoperative period to be one of the surgical time periods of highest anxiety for patients [2-4]. A range in the occurrence of preoperative anxiety has been reported by numerous studies. Mitchell [3] concluded $85 \%$ of 1250 patients sampled for day surgery under general anesthesia experienced some range of anxiety. A separate study with general surgery patients showed $51 \%$ of patients had significant preoperative anxiety [2].

Preoperative anxiety may lead to hemodynamic changes, arrhythmias, increased pain, and increased anesthetic requirements [1,5-7]. Hemodynamic changes seen with increased levels of anxiety are increased blood pressure, heart rate, and respiratory rate. Gooding et al. [7] report that reducing preoperative anxiety can contribute to decreased pain, a decreased incidence of vomiting, fewer complications, and faster recovery times. Psychological impacts for preoperative anxiety are increased distress for patients leading to consequences such as anxiety attacks [8].

Many studies have reported a correlation between preoperative anxiety and increased postoperative pain [9-12]. In a systematic qualitative review of 48 studies, the most common predictor of postoperative pain was preoperative anxiety [9]. Increased pain related to increased anxiety can result in increased narcotic dosing. Narcotics can cause potential problems such as decreased respirations, delayed wake-up from anesthesia, delayed recovery after anesthesia, nausea, vomiting, and ileus. Increased requirements of other types of anesthetics have the potential to cause similar side effects for patients. Alazani [12] reported on a meta-analysis of 14 interventional trials employing different techniques to reduce preoperative anxiety, enrolling 1752 participants in which she found additional implications of preoperative anxiety including delayed wound healing and recovery, leading to longer hospital stays and costly readmissions for patients to the hospital.

In a review by Abrishami \& colleagues [10] preoperative anxiety was a predictor of postoperative pain intensity, having a positive correlation with analgesic consumption postoperatively, and procedures involving cancer correlated with increased analgesic consumption postoperatively. Additional studies have shown that preoperative anxiety is especially prevalent among cardiac, orthopedic, and breast cancer patients $[9,11]$.

\section{Breast Cancer Patients and Preoperative Anxiety}

The American Cancer Society [13] estimates 246,660 new cases of invasive breast cancer and about 61,000 new cases of carcinoma in situ (a non-invasive early form of breast cancer) were diagnosed in women in 2016. The American Cancer Society estimates the number of deaths of women from breast cancer to be 40,450 for 2016. Surgery, either for diagnosis or treatment, is undergone by the majority of women with breast cancer. Even with today's technology and advanced medical treatments designed to decrease unpleasant side effects, breast cancer patients undergoing surgery continue to experience preoperative anxiety, distress, postoperative pain, nausea, and vomiting at a higher rate compared to the general surgical population [9].

Aviado-Langer [14] and Bidstrup et al. [15] report an increased incidence of preoperative anxiety in breast cancer patients of a younger age, without spousal support, and those undergoing more invasive surgery. Drageset et al. [8] found that in women undergoing surgery for primary breast cancer, the waiting period between diagnosis and surgery was the period of highest anxiety and described by the women in the study as frightening, hopeless, long, and hard to endure. Some women, with no previous history of anxiety, experienced anxiety attacks during this period. Drageset et al. [8] reported uncertainty about the future, including surgery and losing the breast, having to adapt to disease, having to tell others about the diagnosis, and a newfound existential awareness were additional stressors reported by breast cancer patients.

Lim, Devi, and Ang [16] completed a systematic review of breast cancer patients that evaluated the level of anxiety among the patient population as well as compared anxiety between patients in this population undergoing different types of treatment. The authors found that anxiety was high in all patients undergoing treatments for breast cancer. Similar to previous research, the studies examined found women who underwent mastectomy had a higher level of anxiety compared to those undergoing breast conserving surgery for breast cancer.

For patients undergoing breast cancer surgery, there are often additional stressors beyond the stress and anxiety associated with other surgeries. The diagnosis of breast cancer has been found to be a stressor cross culturally [8]. A number of researchers have examined the prevalence and effects of preoperative anxiety in surgical patients, but few studies have pinpointed specific patient populations. "To be diagnosed with cancer greatly affects the psyche. Even if the intent of surgery is for cure, the diagnosis impacts a patient's mental state often creating significant distress" [17]. Binns-Turner, Wilson, Pryor, Boyd, and Prickett [18] found that women diagnosed with breast cancer face the stressors and anxiety about future prognosis, mortality, treatment options, and changes in their body image.

\section{Complementary Alternative Treatments}

Complementary, integrative, or alternative medicine includes treatments that are not part of mainstream medicine [19]. Numerous investigators have examined complementary alternative treatments for breast cancer patients undergoing treatment after surgery for breast cancer, patients in recovery from breast cancer, and end of life breast cancer patients. Yoga therapy [20], cognitive therapy [21], music therapy [22], therapeutic touch [23], muscle relaxation [24], mindfulness-based stress reduction [25], guided imagery [26], and other forms of complementary alternative treatments have been evaluated in these patient populations. Many of these investigators found a significant decrease in anxiety when these treatments were used. However, few studies have examined the advantages of these treatments preoperatively. In many of these studies, pre-surgical anxiety was measured as a baseline comparison to anxiety after an intervention postoperatively or with non-surgical breast cancer treatment. 
Forty to fifty percent of cancer patients use complementary and alternative medicine [27]. Huebner et al. [27] found that within the cancer patient population, breast cancer patients have the highest utilization of complementary treatments, with some studies reporting up to $90 \%$ of breast cancer patients using some sort of alternative treatment. Thirty percent of the participants reported complementary and alternative therapy had not been suggested or discussed with their oncologist. Seventy percent of participants felt their oncologist did not take time to discuss these alternative treatments. The most common therapies being used by participants in the study were selenium, relaxation techniques, prayer, vitamin $\mathrm{C}$, and meditation. The most common reasons for pursuing alternative treatments were to have less side effects and booster the immune system. Using these techniques to decrease stress and anxiety fell in the middle of the rankings of reasons breast cancer patients used these treatments. Participants in the survey included both post-surgical breast cancer patients and breast cancer patients whose treatment plan did not include surgery. Patients using complementary treatments including relaxation techniques, homeopathy, vitamin C, yoga, and Chinese herbs reported the highest satisfaction with alternative treatments.

In addition to the systematic reviews noted above, current systematic reviews examining research on complementary alternative treatments include Bradt et al. [28] and Pittman and Kridli's29 evaluations of music interventions to decrease preoperative anxiety, and Nilsson's30 systematic review of the pain-reducing effects of music. Bradt \& colleagues [28] concluded in their review of 2051 patients that music may be beneficial for reducing preoperative anxiety and have a small effect on reducing diastolic blood pressure and heart rate. Pittman \& Kridli [29] reported similar findings. Inconsistent evidence exists that music lowers blood pressure, heart rate and respirations, but music may be beneficial for decreasing patients' anxiety and creating a calming environment for patients in the preoperative setting. Nilsson [30] reported in half of the 42 randomized controlled trials included in his systematic review music had positive effects in reducing patients' anxiety preoperatively. He suggests further research in this area due to the low cost and potential high benefits of implementing music therapy in the preoperative setting.

Bae et al. [31] completed a meta-analysis examining the efficacy of acupuncture to reduce anxiety preoperatively. In the 14 studies included in this review, with a combined sample size of 1034 participants, acupuncture therapy had significant effects compared to sham acupuncture or no treatment in decreasing preoperative anxiety. Researchers Kwekkeboom \& Gretarsdottir [32] reported on research on relaxation techniques for pain management. Kwekkeboom and Gretarsdottir32 reported in 8 of the 15 studies reviewed, there was support for relaxation technique interventions. However, they found flaws with the methodology of the research and suggested further research. Progressive muscle relaxation was the technique most frequently supported for pain relief. A comprehensive systematic review on reducing anxiety in preoperative patients was undertaken by Alanzi.12 The researcher found that in 8 of 14 studies a preoperative education intervention significantly reduced preoperative anxiety.

\section{Preoperative Anxiety Interventions}

The methods of treating preoperative anxiety fall into the categories of pharmacologic and non-pharmacologic or complementary interventions. Benzodiazepines are frequently used as preoperative pharmacologic interventions to decrease anxiety. Commonly used Benzodiazepines include Lorazepam (Ativan), Diazepam (Valium), and Midazolam (Versed). These medications can produce a synergistic effect with central nervous system depressants such as alcohol, inhaled and injected anesthetics, alpha 2 agonists, and opiates [33]. The pharmacologic elimination of benzodiazepines can be reduced by certain medications such as antacids and anti-seizure medications, causing an increased duration of action for patients on these medications. Elderly patients and patients with decreased liver function may also experience delayed excretion of these drugs, making them less than ideal for these patient populations.

Common complementary techniques include music therapy and deep breathing techniques. Programs currently in place at health care facilities have demonstrated effective decreases in preoperative anxiety. "Steps to Surgical Success" (STEPS) is a program, based on Dr. Jean Watson's Theory of Human Caring, which involves preoperative relaxation training for patients. Patients participate in a one-hour healing therapy session on a preadmission day. The session includes a trained provider who assesses the patient's anxiety, provides a guided imagery CD titled Successful Surgery, an eye pillow, essential oil lavender, a folder containing handouts about the program, and a healing touch session. The patient and provider also co-write a personal healing plan [34]. Using the tools provided, the patient lies down, and the trained provider conducts a relaxation session. The patients are given the tools to take home to continue relaxation training.

Another approach to managing pain is the Benson Relaxation Technique. This is a 20-minute relaxation session involving deep breathing and muscle relaxation. In a study with rheumatoid arthritis patients, Bagheri Nesami, et al. [35], patients showed statistically significant improvements in anxiety and depression. The Therapeutically Intervention, Relaxation, Mental Images, and Spirituality program has been effective in increasing well-being and quality of life for terminally ill patients [36]. Many complementary programs and methods appear to be underutilized to help decrease preoperative anxiety.

"Medical practitioners can no longer ignore alternative practices. We must recognize that certain alternative treatments may be more effective for a specific patient population than the traditional allopathy, and such practices must be made available for use under appropriate circumstances" [36]. The rationale for conducting this review was to examine which complementary treatments are effective and efficient in reducing preoperative anxiety in breast cancer patients undergoing breast-altering surgery. Research has been conducted on the use of complementary treatments in the breast cancer patient population, not related to surgery, and has had positive results in decreasing anxiety [37].

Complementary treatments such as acupuncture, music therapy, guided imagery, hypnosis, and essential oils have all been 
studied as modalities to help decrease preoperative anxiety. Acar, et al. [38] studied the effect of acupuncture on the Yin tang point to reduce preoperative anxiety. This point is located between the eyebrows, at the root of the nose. The authors found significant reductions in preoperative anxiety compared to the controlled group, which received sham acupuncture. Braden, Reichow, and Halm [5] examined the effects of the essential oil Lavandin to reduce preoperative anxiety and found significantly lower anxiety upon operating room transfer compared to the control group, providing a cost-effective, time efficient technique to reduce anxiety that poses little risk to patients. The National Conference on Medical and Nursing Education Blue Ribbon Panel and the White House Commission on Complementary and Alternative Medicine Policy both recommend nursing education include curriculum addressing Complementary and Alternative Medicine (CAM) [17].

Aviado-Langer [14] evaluated surgical breast cancer patients, both with invasive breast cancer and those going for breastconserving surgery over a two-month period. Using the Visual Analog Scale (VAS), 75\% of women scored in the range for preoperative anxiety. Younger patients within the group reported the highest levels of preoperative anxiety. Patients undergoing invasive surgery also reported higher levels of anxiety than those undergoing breast-conserving surgery. Results were clinically significant showing that this patient population could benefit from preoperative screening for anxiety and alternative interventions for preoperative anxiety. The VAS has proven to be a reliable and valid tool for measuring preoperative anxiety [14,39].

When preoperative breast cancer patients were questioned about wanting psychological support or counseling by Bidstrup et al. [15] those who answered yes reported higher levels of anxiety compared to patients not interested in additional support. Bidstrupand collegues [15] also found younger women with breast cancer reported higher levels of anxiety and distress compared to older participants in the study. This study used the Hospital Anxiety and Depression Scale (HADS), which has been established as reliable and valid in cancer patients by previous research [40]. In addition, Bidstrup et al. [15] concluded that women in the study who continued to experience distress eight months after surgery, were women whom reported the greatest anxiety and distress before surgery, suggesting vulnerable women are already vulnerable prior to surgery [15].

Currently there are very few preoperative guidelines for reducing anxiety in the preoperative period for specific populations. The breast cancer patient population has been found to be at high risk for postoperative nausea and vomiting, as well as have an increased rate of preoperative anxiety compared to other patient populations. Preoperative anxiety has been shown to increase anesthetic requirements, including narcotics, leading to such problems as nausea and vomiting. The purpose of this systematic review is to evaluate complementary alternative treatments currently being used to decrease anxiety preoperatively in breast cancer patients undergoing breast-altering surgery and report which methods have been effective so Certified Registered Nurse Anesthetists, anesthesiologists, and preoperative nurses can incorporate these treatments into their practices.

\section{Methods}

A review was conducted using systematic methods to address the PICO clinical question, do preoperative complementary alternative treatments help to reduce anxiety in breast cancer patients undergoing breast-altering surgery? and the PRISMA statement [41] was used as a guide for reporting. After reviewing research on preoperative anxiety, findings were the majority of research on these techniques had been completed on cardiac, orthopedic, and breast cancer surgical patients.

\section{Search}

The PubMed, Embase, and CINAHL databases were searched with multiple searches included the terms "preoperative \& anxiety", "anxiety and breast cancer", "preoperative anxiety and breast cancer", "preoperative and relaxation techniques". Other keywords used in the search included "distress", "integrative", "alternative", "complementary" combined with terms including "treatments", "therapies", "practices", "surgery", "biopsy”, "procedures."

\section{Study selection}

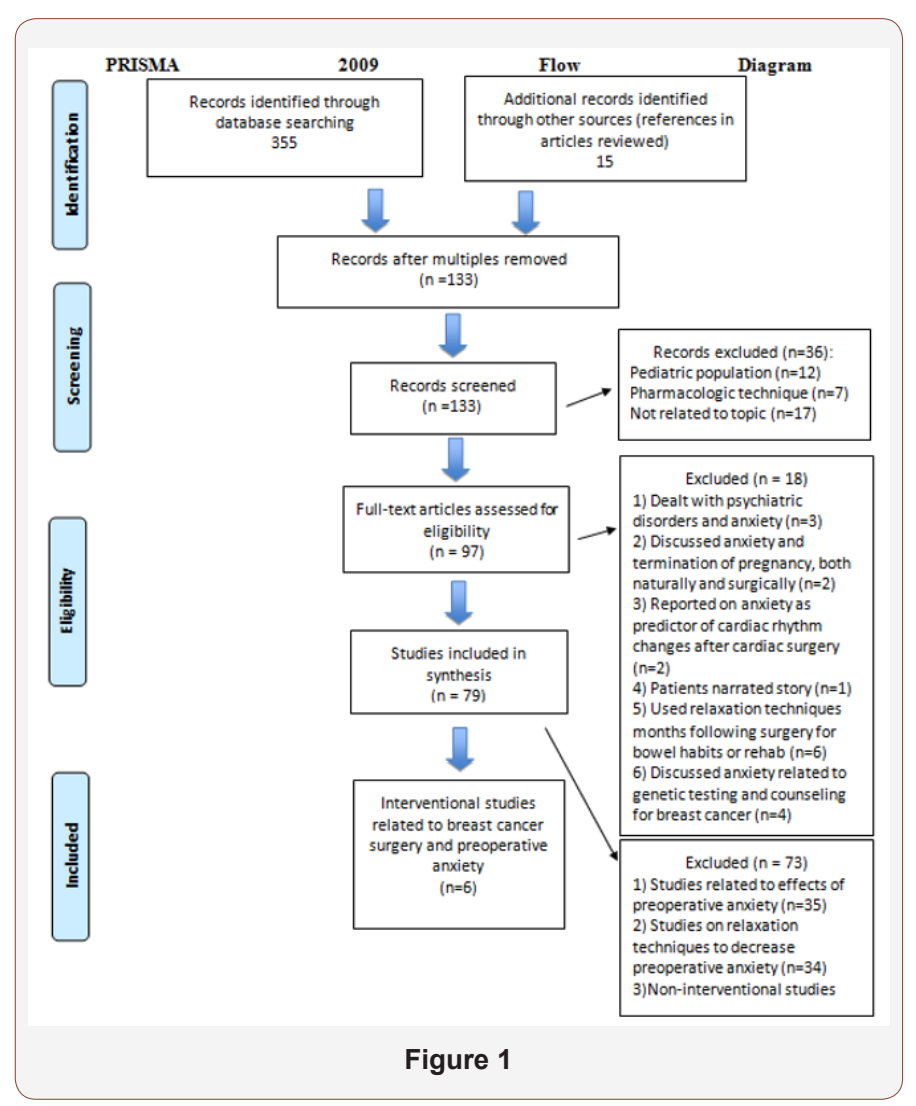

The PubMed, Embase, and CINAHL searches resulted in 335 journal articles (Figure 1). An additional 15 articles were found in the references of the reviewed articles. Multiples were removed, resulting in 133 articles. Upon further review, 12 articles were excluded because they used a pediatric sample, 7 were excluded because they used pharmacologic interventions to decrease anxiety, and 17 articles were not related to the topic. The remaining 97 articles were assessed for eligibility. After reviewing the text of these articles, 3 were specific to psychiatric disorders and anxiety, 2 researched preoperative anxiety specific to pregnant patients, 3 examined anxiety as a predictor of cardiac rhythm changes in cardiac 
surgery, 1 was a self-report, 6 examined relaxation techniques to improve bowel habits following surgery, and 4 discussed anxiety for genetic testing and counseling for breast cancer, not for surgery. All of these were excluded, leaving 79 studies included in the synthesis.

From the 79 articles, 35 examined the effects of preoperative anxiety, 34 studied relaxation techniques to decrease preoperative anxiety, and only 10 were specific to relaxation techniques for preoperative anxiety in the breast cancer patient population. The remaining 10 included 4 non-interventional studies and 6 interventional studies. The 6 interventional studies were included in the review. Citations were managed using the RefWorks citation manager.

\section{Eligibility criteria}

The inclusion for this review were scholarly, peer-reviewed journal articles published in the last 10 years. The research was limited to studies published on adults 18 years of age and older, and articles published in the English language. The systematic review excluded results on male breast cancer patients because of a lack of available material on this patient population. Studies focusing on parents of pediatric patients undergoing surgery were excluded. Types of surgery other than breast surgery, and studies involving solely pharmacological interventions to decrease preoperative anxiety were excluded as well. Studies included in the systematic review were studies with quantitative designs, or a combination of qualitative and quantitative design. Inclusion criteria for interventions/phenomenon of interest included all complementary therapies studies in this patient population. Current research included hypnosis, deep breathing, guided imagery, meditation, emotional and informational sessions, videotaped information, and music therapy.

\section{Risk of bias of individual studies}

Articles were appraised for risk of bias using the Johns Hopkins' Research Appraisal Tool. Some of the biases that may have occurred are in the research design, the Hawthorne Effect, and selection bias. The sampling methods of the research may include volunteer bias and nonresponse bias, and measurements may have been skewed by social desirability bias and observer bias. The studies were each evaluated for strength of evidence using the Johns Hopkins Nursing Evidence-Based Practice Research Evidence Appraisal Tool. The strongest evidence, Level 1, were studies that had an independent variable that was manipulated, a control group, and participants randomly assigned to both the control and intervention group. All the studies included in this review were Level 1 evidence.

\section{Results}

Table 1: Articles Included in Review.

\begin{tabular}{|c|c|c|c|c|}
\hline Author & $\begin{array}{c}\text { Level of Evidence/ Study Design/ Participants/ } \\
\text { Inclusion Criteria }\end{array}$ & $\begin{array}{l}\text { Intervention and Control } \\
\text { Groups }\end{array}$ & Outcome Measures & Results \\
\hline $\begin{array}{l}\text { Binns-Turn- } \\
\text { er et al. } \\
{[18]}\end{array}$ & $\begin{array}{c}\text { Level I } \\
\text { Quasi-experimental design } \\
\mathrm{N}=30 \text { women ages } 42-70 \text { primary diagnosis of } \\
\text { breast cancer } \\
\text { M age }=56 \\
\text { Music therapy } \\
\text { Intervention group n= } 15 \\
\text { Inclusion criteria: Women w/ diagnosis of breast } \\
\text { cancer undergoing mastectomy } \\
\text { Exclusions: ASA } 4 \text { \&5 previous breast cancer, } \\
\text { patients on benzodiazapines, COPD, mental disor- } \\
\text { ders, hearing aids, antipsychotics }\end{array}$ & $\begin{array}{l}\text { Intervention } \\
\text { Wore headphones pre-in- } \\
\text { tra- and postoperatively } \\
\text { with choice of } 4 \text { genres } \\
\text { Control } \\
\text { Usual care but wore head- } \\
\text { phones with no music to } \\
\text { minimize bias from staff }\end{array}$ & $\begin{array}{l}\text { State Anxiety Scale (SSAS) } \\
\text { Visual Analog Scale (VAS) } \\
\text { to measure pain } \\
\text { Measured at baseline } \\
\text { (preoperatively) day of } \\
\text { surgery and postopera- } \\
\text { tively when patient was } \\
\text { ready for discharge from } \\
\text { the post-anesthesia care } \\
\text { unit (PACU) }\end{array}$ & $\begin{array}{l}\text { Baseline measurements } \\
\text { show no differences in } \\
\text { anxiety between groups } \\
\text { Mean arterial pressure } \\
\text { (MAP), pain, and anxi- } \\
\text { ety showed statistically } \\
\text { significant decreases in } \\
\text { intervention group }\end{array}$ \\
\hline $\begin{array}{l}\text { Lew et al. } \\
\quad[17]\end{array}$ & $\begin{array}{c}\text { Level II } \\
\text { Mixed-method design } \\
\mathrm{N}=40 \text { women ages } 30-79 \\
75 \% \text { of participants over } 50 \text { years old } \\
\text { Hypnosis } \\
\text { Intervention group } \mathrm{n}=20 \\
\text { Inclusion criteria: Breast cancer patients receiving } \\
\text { general anesthesia, age } 18 \text { yrs \& }<\text {, undergoing } \\
\text { lumpectomy w } / \text { sentinel node biopsy, } \\
\text { mastectomy w } / \text { and w/out lymph } \\
\text { node dissection } \& \text { able to read/ speak } \\
\text { English }\end{array}$ & $\begin{array}{c}\text { Intervention } \\
\text { 15minute scripted hypnosis } \\
\text { experience within } 1 \text { hour } \\
\text { of surgery in preoperative } \\
\text { holding area } \\
\text { Control } \\
\text { Historical control group }\end{array}$ & $\begin{array}{l}\text { Semi-structured interview } \\
\text { Condensed Memorial } \\
\text { Symptom Assessment } \\
\text { Scale Modified (CMSAS-M) } \\
\text { Measured pre-interven- } \\
\text { tion preoperatively and } \\
\text { prior to discharge from } \\
\text { the PACU } \\
\text { Data collected from } \\
\text { patients and records: } \\
\text { demographic, symptom } \\
\text { assessment, medication } \\
\text { administration, surgical } \\
\text { anesthesia, recovery } \\
\text { minutes }\end{array}$ & $\begin{array}{c}\text { Significant decrease } \\
\text { in anxiety, worry, and } \\
\text { nervousness } \\
\text { Additional decrease in } \\
\text { sadness, irritability, and } \\
\text { feelings of distress } \\
\text { Pain had a 20\% increase } \\
\text { from baseline but } \\
\text { similar mean to control } \\
\text { group }\end{array}$ \\
\hline
\end{tabular}




\begin{tabular}{|c|c|c|c|c|}
\hline $\begin{array}{l}\text { Garssen et } \\
\text { al. [42] }\end{array}$ & $\begin{array}{l}\text { Level I } \\
\text { Randomized controlled trial } \\
\text { N=70 women with primary breast cancer 18-75 } \\
\text { years old } \\
\text { Stress management intervention group n=34 } \\
\text { Inclusion criteria: Clinically proven breast cancer } \\
\text { stage I-III, based on triple diagnostics, no major } \\
\text { psychiatric disorder, no immune morbidities or } \\
\text { other malignant tumors currently or in patient's } \\
\text { history, no use of steroid, primperan, or non-ste- } \\
\text { roidal anti-inflammatory drugs }\end{array}$ & $\begin{array}{l}\text { Intervention } \\
\text { Stress management training } \\
\text { consisting of } 4 \text { sessions of } \\
\text { relaxation, guided imagery } \\
\text { techniques, \& counseling } \\
\text { designed to improve coping, } \\
\text { relaxation, \& a positive at- } \\
\text { titude done on pre-surgery } \\
\text { day } 5 \text { \& } 1 \text { \& post-surgery } \\
\text { day } 2 \text { \& } 30 \\
\text { Control } \\
\text { Usual care }\end{array}$ & $\begin{array}{l}\text { Stait-Trait Anxiety Inven- } \\
\text { tory } \\
\text { Depression subscale from } \\
\text { the Profile of Mood States } \\
\text { (POMS) } \\
\text { Joy-Life subscale from the } \\
\text { Health \& Disease Inven- } \\
\text { tory-General to measure } \\
\text { well-being } \\
\text { Two 10-point scales on } \\
\text { pain intensity \& duration } \\
\\
\text { Questionnaire given } \\
\text { before intervention at day } \\
6 \text { before surgery \& again } \\
\text { at day } 1 \text { before surgery } \\
\text { \& post-surgical days 2, } 5 \text {, } \\
30,90\end{array}$ & $\begin{array}{l}\text { Anxiety decreased } \\
\text { similarly in intervention } \\
\& \text { control groups } \\
\text { Clear decrease in de- } \\
\text { pression in intervention } \\
\text { group. Control group } \\
\text { showed decrease at } 3 \\
\text { months after surgery. } \\
\text { Difference was signifi- } \\
\text { cant at Day } 5 \text { post-sur- } \\
\text { gery } \\
\text { Quality of life increased } \\
\text { at Day } 2 \text { \& } 30 \text { in inter- } \\
\text { vention group only } \\
\text { Intervention group } \\
\text { experienced significant- } \\
\text { ly more control after } \\
\text { surgery at day 2, 5, 30, } \\
\& 90\end{array}$ \\
\hline $\begin{array}{c}\text { Hsu et al. } \\
\text { [43] }\end{array}$ & $\begin{array}{l}\text { Level I } \\
\text { Quasi-experimental design } \\
\mathrm{N}=63 \text { women diagnosed with breast cancer } \\
\text { Informational \& emotional consultation experi- } \\
\text { mental group n=32 } \\
\text { M age }=47 \\
\text { Inclusion Criteria: Breast cancer diagnosis, cur- } \\
\text { rently undergoing modified radical mastectomy } \\
\text { for } 1^{\text {st }} \text { time, chemotherapy not received before } \\
\text { surgery, no breast reconstruction after mastec- } \\
\text { tomy, able to communicate verbally, willing to } \\
\text { participate }\end{array}$ & $\begin{array}{c}\text { Intervention } \\
\text { A two-session informational } \\
\text { \& emotional consultation } 2 \\
\text { days before surgery and } 3 \\
\text { days following surgery } \\
\text { Control } \\
\text { Routine care }\end{array}$ & $\begin{array}{l}\text { Demographic Inventory } \\
\qquad \text { (DI) } \\
\text { Body Image scale (BIS) } \\
\text { Anxiety-Visual Analogue } \\
\text { Scale (A-VAS) } \\
\text { Emotional Distress Scale } \\
\text { Pretests given before } \\
\text { first consultation session } \\
\text { (T1), at time of discharge } \\
\text { (T2), and 3 months after } \\
\text { surgery (T3) }\end{array}$ & $\begin{array}{l}\text { At baseline groups were } \\
\text { similar in responses } \\
\text { Significant difference in } \\
\text { anxiety from T1 to T2 } \\
\text { between group } \\
\text { Anxiety, body image, \& } \\
\text { emotional distress had } \\
\text { positively significant } \\
\text { differences from T2 to } \\
\text { T3 \& from T1 to T3After } \\
\text { the intervention women } \\
\text { had immediate and } \\
\text { prolonged positive im- } \\
\text { provements in anxiety } \\
\text { \& prolonged improve- } \\
\text { ments in emotional } \\
\text { distress \& body image }\end{array}$ \\
\hline $\begin{array}{l}\text { Palmer et } \\
\text { al. [44] }\end{array}$ & $\begin{array}{l}\text { Level I } \\
3 \text { Group randomized controlled trial } \\
\mathrm{N}=201 \text { women undergoing surgery for potential } \\
\text { or known breast cancer } \\
\text { M age }=59 \\
\text { Recorded music therapy intervention group } \mathrm{n}=69 \\
\text { Live music intervention group } \mathrm{n}=69 \\
\text { Inclusion criteria: re-excisions, English speaking, } \\
\text { ASA II-III, no mental illness, no developmental } \\
\text { disability, \& no significant hearing loss }\end{array}$ & $\begin{array}{c}\text { Intervention } \\
\text { Patient either listened to } \\
\text { their choice of live music } \\
\text { preoperatively \& therapist } \\
\text { selected recorded music } \\
\text { intraoperatively or listened } \\
\text { to their choice of recorded } \\
\text { music preoperatively \& } \\
\text { therapist selected recorded } \\
\text { music intraoperatively } \\
5 \text { minutes of music listening } \\
\text { preoperatively followed by } \\
\text { conversation about process- } \\
\text { ing song \& questions about } \\
\text { patients song choice } \\
\text { Control } \\
\text { Usual care and wore } \\
\text { noise-canceling headphones }\end{array}$ & $\begin{array}{c}\text { Anxiety-VAS } \\
\text { Bispectral Index } \\
\text { Recovery time } \\
\text { Patient satisfaction survey } \\
\text { given before discharge } \\
\text { A-VAS used preoperatively } \\
\text { before \& after intervention } \\
\text { or control }\end{array}$ & $\begin{array}{l}\text { Both experimental } \\
\text { groups showed de- } \\
\text { creases in anxiety from } \\
\text { baseline } \\
\text { Between live \& recorded } \\
\text { music groups no signifi- } \\
\text { cant differences } \\
\text { Time to readiness } \\
\text { discharge was shorter } \\
\text { in live music group }\end{array}$ \\
\hline
\end{tabular}




\begin{tabular}{|c|c|c|c|c|}
\hline $\begin{array}{c}\text { Wysocki et } \\
\text { al. [45] }\end{array}$ & $\begin{array}{c}\text { Level I } \\
\text { Randomized controlled trial } \\
\mathrm{N}=58 \text { women } 18 \text { years \& older admitted for } \\
\text { mastectomy } \\
\text { Intervention group n= } 29 \\
\text { M age= 55( control group) } 60 \text { (intervention } \\
\text { group) } \\
\text { Inclusion criteria: cytological or histological prov- } \\
\text { en invasive breast cancer, able to use VAS, able to } \\
\text { fill out questionnaire, undergoing mastectomy, no } \\
\text { disseminated breast cancer or other treatments } \\
\text { given, no vision or hearing impairment, no previ- } \\
\text { ous malignancies, no medical education }\end{array}$ & $\begin{array}{c}\text { Intervention } \\
\text { Structured information } \\
\text { delivered preoperatively } \\
\text { with a } 12 \text { minute video } \\
\text { (usually the afternoon } \\
\text { before surgery) } \\
\text { Control } \\
\text { Usual care }\end{array}$ & $\begin{array}{l}\text { VAS to measure anxiety } \\
\text { VAS \& questionnaire to } \\
\text { measure patients' knowl- } \\
\text { edge } \\
\text { Measured preoperatively, } \\
\text { 24-36 hours postoper- } \\
\text { atively, } 7 \text { days following } \\
\text { surgery, \& } 30 \text { days follow- } \\
\text { ing surgery }\end{array}$ & $\begin{array}{c}\text { No significant effect } \\
\text { on anxiety or patient } \\
\text { knowledge except ex- } \\
\text { perimental group knew } \\
\text { more about treatment } \\
\text { options }\end{array}$ \\
\hline
\end{tabular}

Six studies (Table 1) related to breast cancer surgery and preoperative complementary alternative treatments for anxiety were found through electronic database searches and secondary references. The majority of studies were conducted on white women, ages 18-75 years old. The complementary relaxation treatments employed included music, stress management training, emotional and informational support sessions, and hypnosis. One study examined the effect of a preoperative informational video on surgical expectations, disease progression, and treatment options on surgical breast cancer patients' anxiety.

\section{Results of individual studies}

Four of the six preoperative relaxation interventions examined, in this review, demonstrated a significant reduction in patient anxiety symptoms compared to the control condition. BinnsTurner et al. [18] used a quasi-experimental design to examine the effects of listening to music preoperatively on mean arterial pressure, heart rate, anxiety, and pain on breast cancer patients undergoing mastectomy. The patients were allowed to choose from four genres of music. The researchers found a significant decrease in anxiety from the preoperative period to the postoperative period in women that received the music intervention. Palmer et al. [44] studied the effects of live music, recorded music, or no music at all preoperatively, to decrease anxiety in women undergoing procedures for potential or known breast cancer under monitored anesthesia care. Patients were allowed to make their own music selection preoperatively and therapist chosen recorded music was played throughout the procedure. The authors found decreased anxiety in both intervention groups, with no significant difference in which format the patient heard the music, live vs. recorded.

Hsu et al. [43] reported positive effects on reducing anxiety in breast cancer patients undergoing modified radical mastectomy both immediately and two months following surgery after preoperative emotional and informational sessions. Lew et al. [17] conducted a retrospective patient records review as their control group to compare against an interventional group that received a 15-minute guided hypnosis session within one-hour before surgery. Medication administration, time in recovery, and type of anesthesia was compared between the two groups. A scripted hypnosis session was individualized for each patient by incorporating patient preferences for guided imagery in the beginning of the hypnosis session. Relevant to the research question, the authors found that preoperative hypnosis did decrease preoperative anxiety.
A similar, short-term decrease in anxiety in both the experimental and control groups was reported by Garssen et al. [42]. The researchers also did not observe the intervention to significantly decrease pain. In the mixed-method research conducted by Wysocki et al. [45]. the researchers examined the effects of preoperative information regarding breast cancer, progression of the disease, and treatment options based on information from the National Cancer Institute when delivered in a video preoperatively. The authors found no significant results on information delivered preoperatively to decrease anxiety preoperatively or postoperatively.

\section{Summary of Evidence}

The six studies included a total of 462 participants. All of the studies addressed the additional stressors experienced by women undergoing surgery for breast cancer treatment. The different complementary alternative treatments used were hypnosis guided by personal preference of participants[17], emotional and informational support sessions[43], an educational video about hospital stay, treatment options, and postoperative care [45], and stress management training sessions including relaxation training, guided imagery, and counseling to promote active coping and a positive attitude to change[42].Two studies used music therapy[18'44].

\section{Study Characteristics}

The person or persons delivering the research intervention in the six intervention studies included an oncologist and two oncology-nursing specialists, a clinical psychologist, a doctor, a nurse, a hypnotic interventionist, music therapists, and a breast cancer survivor. An oncologist and two oncology-nursing specialists were used to provide the therapeutic intervention in one trial and allowed patients to contact the staff providing therapy at any time by telephone [43]. A clinical psychologist performed stress management training sessions in the study conducted by Garrsen et al. [42]. Lew and colleagues comprised a team of one anesthesiologist, one data collection nurse and one hypnotic interventionist to promote consistency within the study and decrease risk of bias. A breast cancer survivor presented a structured informational video 45 and music therapists were utilized by two of the research studies [18,44].

Although two studies used music $[18,44]$, there were a number of differences in how the music was delivered, ability to select 
music, and when anxiety symptoms were recorded. The study design differed between the studies in many ways including the format the relaxation technique was delivered in. Two of the six studies incorporated relaxation techniques over multiple sessions [42-43]. Two studies had a room designated for intervention $[43,45]$. Palmer \& collegues [44] had two intervention groups and a control group. Hsu et al. [43] allowed spouses to accompany the patients to their therapeutic sessions that ran two hours long. Garrsen et al. [42] conducted 45 minutes to one-hour sessions and included a CD for participants to take home to practice relaxation exercises. One of the studies using music as an intervention allowed participants to listen to five minutes of either live or recorded music preoperatively, depending on the intervention group they were assigned to, and included discussion about song choice and processing of the song[44].The other music intervention [18] initiated the patient's choice of four genres of music preoperatively and ended it postoperatively. Lew and colleagues [17] had a 15-minute nurse-delivered hypnosis protocol in the holding area within one hour prior to surgery. Wysocki and team [45] showed 12-minute-long video 12-18 hours prior to surgery.

All of the studies examined anxiety; however, each study looked at additional variables as well. Four of the studies used preoperative anxiety as a baseline to compare against postoperative anxiety measurements $[17,18,43,45]$. One used it as baseline to compare to preoperative, post-intervention anxiety and postoperative anxiety [42], and one study used pre-intervention preoperative anxiety to compare to anxiety preoperatively, post intervention [44]. Additional variables examined included body image, anxiety, and emotional distress [43]. Garrsen [44] and colleagues additionally studied the effects of their intervention on depression, quality of life, perception of control, fatigue, pain, sleep problems, and surgery related somatic symptoms. Two of the studies looked at the effects of their intervention on recovery time [17,44]. Lew et al. [17] conducted a symptom assessment consisting of anxiety, worry, nervousness, sadness, irritability, distress, nausea, and pain. Vital signs including blood pressure, using mean arterial pressure, and heart rate, as well as pain, were outcomes measured by BinnsTurner \& colleagues [18].

Many different types of evaluations were used to measure the variables in the studies included in this review including the Body Image Scale [43], the Emotional Distress Scale [43], (Hsu et al., 2010), and the Visual Analog Scale (VAS)[43-45].The VAS was used in different studies to measure anxiety and by Binns-Turner \& colleagues [18] to measure pain. Garrsen et al. [42] used the Profile of Mood States (POM), the Joy in Life Subscale and the Subjective Sleep Quality Scale. The State Trait Anxiety Inventory Test (STAIT) was used to measure anxiety in two studies $[18,42]$. Lew \& colleagues [17] used a modified version of the Condensed Memorial Symptom Assessment Scale to measure symptoms such as anxiety, pain, nausea, and distress. Wysocki and team measured subjective knowledge using a questionnaire.

Additional variables besides anxiety were also measured, including sedative effects on the brain, recovery time, and patient satisfaction with the experiment. The Bispectral Index [44] was used to measure effects of sedatives on brain. Recovery time was measured as the amount of time from the end of surgery end to the time the patient met discharge criteria. Four of the studies included participant evaluations of the experience. Hsu et al. [43] used the Intervention Satisfaction Scale and found participants were highly satisfied with the intervention. Garrsen \& team [42] included an evaluation of the experience and showed that participants were very satisfied with intervention. Patient satisfaction was measured with a questionnaire in Palmer and colleagues' [44] research and resulted in equal satisfaction in both the control and intervention groups. Positive feedback about the participants' hypnotic experience from an intervention interview was received by Lew and colleagues. A recommendation gained from the interview was to conduct the session in a private room.

Measurements of the different variables examined in each study were taken at different times in each of the studies. Research by Hsu et al. [43] used face-to-face interviews to measure variables at three different points in time: the day before surgery, the day of discharge, and two months following surgery. Garrsen \& colleagues [42] measured variables using questionnaires at six points in timeas a baseline at day six pre-surgery, post first training session day one pre-surgery, and day two, five, 30 and 90 post-surgery. Wysocki and team [45] used four points in time to compare anxiety and knowledge: as a baseline the day before surgery, 2436 hours postoperatively, seven days postoperatively, and 30 days postoperatively. Palmer et al. [44] measured preoperative anxiety prior to the intervention as a baseline and then again preoperatively, post-intervention. Binns-Turner \& colleagues [18] measured preoperatively and at time of discharge when the patients Aldrete score was nine or greater. Lew et al. [17] recorded symptoms preintervention preoperatively and post-intervention postoperatively.

\section{Study Selection}

Inclusion criteria differed between studies for patient selection regarding breast cancer diagnosis and surgical treatment. Three of the studies limited inclusion to only patients undergoing modified radical mastectomy diagnosed with breast cancer $[18,43,45]$. Two studies included participants undergoing lumpectomy or mastectomy with sentinel node procedure or axillary node dissection [42,44]. Additionally, Palmer and colleagues [44] included patients undergoing breast biopsies and re-excisions. Excluded from two of the studies patients were patients receiving chemotherapy [42-43] or undergoing reconstructive surgery $[17,43]$. Wysocki and team excluded patients undergoing breastconserving therapy and neoadjuvant treatment for breast cancer.

The diagnosis of breast cancer also differed between studies as to what patient diagnoses were included in the individual research studies. Two studies, Garrsen et al. [42] and Wysocki et al. [45] required patients be diagnosed with breast cancer based on triple diagnostics (physical exam, mammogram, \& cytology or biopsy). One study allowed potential or known breast cancer [44]. Also excluded from Garrsen et al. [42] and Wysocki et al. [45] were patients with immune comorbidities or other malignancies in the past or present. In the research conducted by Binns-Turner and colleagues participants could have no previous diagnosis of, or treatment for, breast cancer. The participants in Wysocki \& colleagues [45] research were limited to patients undergoing 
mastectomies as the primary treatment for the breast cancer and had no previous surgery for any type of cancer.

Other medical conditions, not related to cancer, excluded patients from participating in the studies. In three studies patients with psychiatric disorders were excluded [17,18,42]. Garrsen \& colleagues [42] additionally excluded patients taking immunotherapy, steroids, NSAIDS or primpera. Profound mental illness, developmental disability, significant hearing loss, and taking narcotics were exclusions to participate in the research of Palmer \& colleagues [44]. Binns-Turner [18] and team also excluded patients with chronic obstructive pulmonary disease, those with hearing aids, and patients taking benzodiazepines or antipsychotics. Patients with uncontrolled major health issues such as congestive heart failure were excluded from the work of Lew \& colleagues [17]. Hearing and vision impairment were exclusions from the research of Wysocki \& team [45]. Unrelated to patients' health, excluded from the work of Wysocki et al.[45] were patients with medical education. One commonality was all of the studies participants had to be physically and psychologically able to complete the questionnaires and interviews.

\section{Risk of Bias of Individual Studies}

Bias was controlled for by multiple methods including using similar demographics between groups, comparing inter-rater reliability, and statistical analysis to look for and correct for differences that may have occurred. All of the studies examined differences in demographics between the experimental and control groups. Four studies showed no significant difference in demographics between experimental and control groups $[17,18,43,44]$. Wysocki et al. [45] found the proportion of participants marital status not dispersed evenly between the control and the experimental group. This may have impacted their findings as previous research [15] has shown spousal support to be helpful in decreasing anxiety. In the remaining study, there was no difference in demographics except higher alcohol intake in the experimental group [42].

To achieve randomization each researcher used different methods of randomization. Palmer and team used a computerized online randomization module. Wysocki \& collegues [45] used Stats Direct software to generate a randomization code. Block randomization in which week-by-week patients were assigned either to the control or intervention group was the method used by Garrsen et al. [42] This helped prevent contact between participants. Also helpful in preventing contact between study participants were the studies that used two locations to complete the research [43-44]. Lew and team 17 used a historical control group to compare reports of pain intensity, recovery time, and medication administration; however, the intervention group was compared against its own preoperative baseline scores for symptoms. Independent and paired t-tests were used to evaluate data in three reports $[18,42,45]$. Palmer et al. [44] used Pairwise Wilcoxon rank sum tests used to compare the outcomes between groups to account for differences in hospitals and surgeons. Garrsen \& colleagues [42] used analysis of covariance to statistically compare the results of the State Trait Anxiety Inventory.

\section{Discussion}

To answer the research question of Do relaxation techniques help to decrease preoperative anxiety in breast cancer patients undergoing breast altering surgery? leading to decreased postoperative anxiety, pain, and the consequences of each, requires further clinical trials and is an area more research is needed. Based on the Level 1 evidence reviewed, complementary alternative treatments may be successful in reducing preoperative anxiety in breast cancer patients undergoing breast-altering surgery. The breast cancer patient population is a patient population that has increased anxiety due to diagnosis and prognosis. "The prevalence of distress symptoms in cancer patients is often reported to be above $30 \%$, that of depressive symptoms to be $10-25 \%$, and that of anxiety to be 10-30\%." [15]. Factors such as younger age, lack of a support system, and more invasive surgery lead to increased anxiety within this patient population.

\section{Summary of Evidence}

Four of the six studies found significant decreases in anxiety following a preoperative relaxation technique intervention. BinnsTurner \& team [18] reported that perioperative music resulted in a significant decrease in anxiety both postoperatively in the postanesthesia care unit and at time of discharge. Also using music therapy, Palmer \& researchers [44] found a preoperative, postintervention decrease in anxiety that was significant after just 5 minutes of music was listened to. Both the participants in the live music group and participants in the recorded music group had similar significant decreases in anxiety. In Lew and colleagues' [17] research on preoperative hypnosis a significant decrease in anxiety was observed in the intervention group post-intervention preoperatively. The information and emotional support sessions researched by Hsu and colleagues [43] yielded an immediate and prolonged (two months following intervention) decrease in anxiety. Not successful in finding significant reductions in anxiety were the stress-management training sessions conducted by Garssen [42] and team and the preoperative information video delivered by a breast cancer survivor as presented by Wysocki \& team [45].

Other findings reported by the studies included decreases in blood pressure and pain, as well as increases in knowledge. Binns-Turner \& collegues [18] found a decrease in mean arterial pressure and pain compared to the control group at time of discharge. Palmer et al. [44] did not find a difference in sedative (propofol) requirements to decrease the BIS monitor to a level of 70 between control and intervention groups. Wysocki et al. [45] did not find a decrease in anxiety or a significant increase in subjective knowledge after an informational video intervention. The only significant finding was the experimental group knew more about treatment options than the control group. Lew and colleagues found a decrease postoperatively after a hypnosis intervention in anxiety, nervousness, sadness, irritability, and distress, but an increase in pain and nausea compared to the intervention group's own baseline reports of these symptoms and in-patient records from the historical control group.

The findings of this small systematic review are summarized below: 
1. Preoperative breast cancer patients of younger age, breast cancer patients undergoing invasive surgeries, and those without a support system appear to have higher anxiety within the surgical breast cancer patient population.

2. Complementary therapies such as relaxation training programs, music, and hypnosis have been effective in reducing anxiety for preoperative breast cancer patients.

3. Music may be live or recorded and should be the patient's choice of genre.

4. When adhered to a mindfulness-based stress reduction program can be beneficial in reducing anxiety in this patient population.

5. The waiting period between diagnosis and surgery is a high anxiety time period for this patient population, climaxing the day before surgery

6. Additional videotaped preoperative information regarding the disease process may not be helpful in decreasing anxiety in patients undergoing mastectomy

7. Hypnosis is a noninvasive, almost risk-free method to decrease anxiety

\section{Limitations}

Limitations of the systematic review include the small number of articles included in the review, the studies' designs and characteristics, the sample sizes of the individual research articles, and the numerous instruments used to measure anxiety and the other variables examined by the researchers. Four studies have the limitation of a small sample size, which prevented further analysis between subgroups such as age and spousal support [18,42,43,45]. All studies were conducted only on women and involved selfreport from the participants. Three studies consisted of mostly white middle-class women $[17,18,44]$. Lew and colleagues [17] used a historical control group, which questions the quality of this research as there may have been different staff and different medications both used for anesthesia and in the post-anesthesia care unit at the time point of the historical control group. Also because of this design there was no baseline to post-intervention findings to compare between groups. One would expect a patient to report more pain after surgery than before surgery but there was no between group postoperative comparisons made.

Numerous instruments have been validated to measure preoperative anxiety. While some of these scales allow for comparison, others do not. The VAS, as introduced by Kindler, Harms, Amsler, Ihde-Scholl, and Scheidegger, measures anxiety before surgery. The VAS and STAI have been compared and showed to have similar results when measuring anxiety. The VAS and the Hospital Anxiety and Depression Scale (HADS) have been shown to be clinically equivalent measuring preoperative anxiety [45].Various tools in this systematic review to report anxiety include the STAI, the VAS, HADS, the Beck Anxiety Inventory (BAI), the Depression, Anxiety, and Stress Scale (DASS), the distress thermometer, and the Condensed Memorial Symptom Assessment Scale- Modified (CMSAS-M). The reliability and validity of measuring anxiety with the VAS, STAI, CSMAS-M, and the distress thermometer has been established [17-18]. The HADS has been studied specifically in cancer patients and found to be valid and reliable in this patient population [17]. The lack of one uniform measure to report preoperative anxiety can lead to inconsistency between results.

Another limitation with the research is feasibility of bringing complementary alternative treatments into practice. As Lew et al. [17] pointed out in their own research, nurses have not historically delivered hypnosis. Nurses have also not been training to guide meditation or imagery or possibly even deep breathing techniques. Time is also an issue, as a hypnosis session can take twenty minutes to guide. Music therapy is not feasible at all institutions whether it be to cost of devices to play music or lack of staff to assist in the process. Until nursing curriculums begin to include trainings in complementary alternative treatments, whether at colleges and universities or at places of employment, it is up to nurses to take their own personal time to learn such techniques that may or may not be welcomed at their place of employment.

The research on complementary alternative treatments has gaps in findings for specific patient populations. More wide range of studies should be completed to see if relaxation techniques and alternative therapies are an idea patient are interested in and willing to spend time doing when not feeling well. Perhaps patients would rather not be involved in these techniques. Using the techniques to decrease surgical anxiety and surgical pain needs further research. There have been favorable findings on these techniques, but with a patient population as vulnerable as breast cancer patients' results can be biased by the need and desire to want to have less anxiety and pain.

\section{Complementary Techniques for Other Patient Populations}

Research has been done on other patient populations such as ambulatory surgery patients, cardiac surgery patients, and men undergoing urologic procedures. Techniques including guided imagery, music, and information sessions have all been shown to be effective in these patient populations. In ambulatory surgery hand massages were given by nursing students and resulted in a decrease in anxiety in the intervention group [46]. A separate study on ambulatory surgery patients in 2010 found preoperative guided imagery resulted in a significant reduction in preoperative anxiety, which can in turn lead to less postoperative pain and faster discharge times [47]. Cooke et al. [48] reported a decrease in anxiety on same day surgical patients when music was listened to preoperatively. In a study of 64 male patients undergoing urogenital surgery the men who chose their own selection of music to listen to for 30 minutes before surgery experienced a significant decrease in preoperative anxiety compared to the control group [49]. In the United States, a sample of 262 participants undergoing cardiac surgery showed a significant decrease in postoperative mental fatigue after using preoperative prayer coping [50].

In Taiwan, blood pressure, pulse, respiration, and anxiety using the STAI, were measured preoperatively before and after patients listened to a relaxation tape. All measurements 
showed a statistically significant decrease after the intervention [51]. Research addressing 20 Spanish-speaking patients at Massachusetts General Hospital shown an anesthesia instructional video in Spanish resulted in a decrease in anxiety and an increase in satisfaction in the intervention group shown the video [52]. Erci et al. [53] studied the effect of an intervention designed to foster a therapeutic relationship in patients undergoing general surgery and found a significant decrease in anxiety in their intervention group. $\mathrm{Ng}$, Chau, and Leung [54] found that giving additional information about surgery and recovery to patients undergoing oral surgery led to decreased anxiety in patients' self reports.

There has also been conflicting research including studies on relaxation techniques such as essential oils [55] and muscle relaxation [56,57] where the intervention has not been effective. Breast cancer patients in general have shown a decrease in anxiety and increase in mood when adhering to a mindfulness-based stress reduction program over several months [37]. The research on the breast cancer patient population has shown to be effective not specific to surgical breast cancer patients, so a possibility is to incorporate a component related to surgical anxiety into a much broader mindfulness-based stress reduction program.

\section{Recommendations for Further Research}

Future research should focus on specific patient populations to tailor relaxation techniques and complementary alternative treatments to best fit the need of patients. Also research on the best instrument to measure anxiety needs further study to allow a uniform comparison between studies. The format, including private setting versus holding area, single or multiple sessions, and when preoperatively these treatments are most effectively delivered are also areas further research is needed. The authors of each of the studies contributed their own recommendations for further research.

Hsu and colleagues reported women with breast cancer can decrease their emotional distress when given the tools and support to help them deal with the emotional distress of breast cancer. The researchers recommended clinical nurses provide information and emotional support before surgery to prevent the progression of anxiety and support should extend to home by email or telephone consultation as well as to pay attention to individual patient needs and needs of individualized patient populations to help decrease anxiety and its adverse effects on well-being. The researchers also suggested further research to explore the differences in anxiety, body image, and emotional distress between women undergoing breast-conserving surgery and women undergoing modified radical mastectomy.

Palmer \& team [44] suggested further quantitative research to fortify the therapeutic value of music. Wysocki et al. [45] suggested further initiatives to improve patients' level of knowledge and to decreaseanxietyinsurgical patients, as well as, suggested a combined video and interactive approach to disseminate information in future studies. Lew \& colleagues [17] recommended more research on the ideal timing of hypnotic sessions preoperatively and further research on the use of preoperative hypnosis for the management of anxiety, nervousness, and worry, as well as the further exploration of nurse led preoperative hypnosis. The combined suggestions of further research are a good next step to continue research on relaxation techniques and complementary alternative treatments as ways to decrease preoperative anxiety for patients.

\section{Conclusion}

More research still needs to be conducted in the use of complementary alternative medicine for the use of decreasing anxiety in breast cancer patients undergoing breast-altering surgery. The limited number of studies included in this review utilized multiple interventions, measurement instruments, and study designs. The different techniques including music, video, stress management training, emotional and informational sessions, and hypnosis make it difficult to compare results between studies. The time frame in which these techniques were delivered, over multiple sessions, days, weeks, and months following surgery, preoperatively before the day of surgery, and on the surgical day, also varies greatly making it difficult to the conclude the best time to incorporate these techniques. One instrument has not been shown superior to measure anxiety, which would make a uniform scale in which to compare across studies. These are all areas more research needs to be completed on.

Additional research also needs to be completed for specific patient populations. These therapies have been effective in reducing preoperative anxiety for cardiac surgery patients, as well as intraoperative for patients undergoing electrophysiology studies under sedation, and pain postoperatively for orthopedic surgical patients, and. Music therapy has proved beneficial for reducing anxiety in a variety of settings including preoperatively in ambulatory surgery settings $[48,58]$, and as a non-pharmacologic pain management tool [59] Guided relaxation has been proven effective to reduce anxiety on surgical patients [60-61]. Preoperative hypnosis has been studied to reduce anesthesia side effects and postoperative pain by Lew et al. [17].

There is substantial research related to complementary alternative treatments to decrease preoperative anxiety in general surgery patients but not much research specifically targeted for those patient populations with a higher baseline level of anxiety such as breast cancer patients. In this review music therapy, hypnosis, and information and emotional support sessions were successful in reducing anxiety in breast cancer patients undergoing breast-altering surgery. Relaxation techniques and complementary alternative treatments have been around for a long time but are now being integrated with western medicine to treat the whole person, body, mind, and spirit.

\section{Acknowledgement}

None.

\section{Conflict of Interest}

No conflict of interest.

\section{References}

1. Valenzuela Millan J, Barrera-Serrano JR, Ornelas-Aguirre JM (2010) Anxiety in preoperative anesthetic procedures. Cirugia Y Cirujanos 78(2): 147-151. 
2. Akinsulore A, Owojuyigbe AM, Faponle AF, Fatoye FO (2015) Assessment of preoperative and postoperative anxiety among elective major surgery patients in a tertiary hospital in Nigeria. Middle East J Anesthesiol 23(2):235-240.

3. Mitchell M (2010) General anesthesia and day-case patient anxiety. J Adv Nurs 66(5): 1059-1071.

4. Denieffe S, Cowman S, Gooney M (2013) Symptoms, clusters and quality of life prior to surgery for breast cancer. J Clin Nurs 23:2491-2502.

5. Braden R, Reichow S, Halm MA (2010) The use of the essential oil lavandin to reduce preoperative anxiety in surgical patients. J Perianesth Nurs 24(6): 348-355.

6. Bilgin TE, Altun TA, Saylam B, Erdem E (2012) Effects of preoperative information team on potoperative pain and patient satisfaction. Turk J Urol 38(2): 91-94.

7. Gooding L, Swezey S, Zwischenberger JB (2012) Using music interventions in perioperative care. South Med J 105(9): 486-490.

8. Drageset S, Lindstrom TC, Giske T, Underlid K (2016) Being in suspense: a women's experience awaiting breast cancer surgery. J Adv Nurs 67(9): 1941-1951.

9. Ip HY, Abrishami A, Peng PW, Wong J, Chung F (2009) Predictors of postoperative pain and analgesic consumption. Anesthesiology 111(3): 657-677.

10. Abrishami A, Chan J, Chung F, Wong J (2011) Preoperative pain sensitivity and its correlation with postoperative pain and analgesic consumption: a qualitative systematic review. Anesthesiology 114(2): 445-457.

11. Robleda G, Sillero A, Puig T, Gich I, Banos JE (2014) Influence of preoperative emotional state on postoperative pain following orthopedic and trauma surgery. Rev. Latino AM Enfermagem 22(5):785-791.

12. Alanzi AA (2014) Reducing anxiety in preoperative patients: a systematic review. Br J Nurs 23(7):387-393.

13. http://www.cancer.org/cancer/breastcancer/detailedguide/breastcancer-key-statistics.

14. Aviado-Langer J(2014) Measuring preoperative anxiety in patients with breast cancer using the Visual Analog Scale. Clin J Oncol Nurs 18(5): 489-491.

15. Bidstrup PE, Christensen J, Mertz BG, Rottman N, Dalton SO et al. (2015) Trajectories of distress, anxiety, and depression among women with breast cancer: Looking beyond the mean. Acta Oncologica 54(5): 789796.

16. Lim CC, Devi MK, Ang E (2011) Anxiety in women with breast cancer undergoing treatment: a systematic review. Int J Evid Based Healthc 9(3): 215-235.

17. Lew MW, Kravits K, Garberoglio C, Williams AC (2011) Use of preoperative hypnosis to reduce postoperative pain and anesthesiarelated side effects. Int J Clin Exp Hypn 59(4): 406-423.

18. Binns-Turner PG, Wilson LL, Pryor ER, Boyd GL, Prickett CA (2011) Perioperative music and its effects on anxiety, hemodynamics, and pain in women undergoing mastectomy. AANA J 79(4): 21-27.

19. h t t p s : / / w w w. n l m. n i h. gov/medli n e plu s/ complementaryandintegrativemedicine.html.

20. Kovacic T, Zagoricnik M, Kovacic M (2013) Impact of relaxation training according to the Yoga in Daliy Life system on anxiety after breast cancer surgery. J Complement Integr Med 10(1): 1-12.

21. Groarke A, Curtis R, Kerin M (2013) Cognitive-behavioural stress management enhances adjustment in women with breast cancer. $\mathrm{Br} \mathrm{J}$ Health Psychol 18: 623-641.

22. Li X, Zhou K, Yan H, Wang D, Zhang Y (2011) Effects of music therapy on anxiety of patients with breast cancer after radical mastectomy: a randomized clinical trial. J Adv Nurs 68(5): 1145-1155.

23. Kelly AE, Sullivan P, Fawcett J, Samarel N (2004) Therapeutic touch, quiet time, and dialogue: perceptions of women with breast cancer. Oncol Nurs Forum 31(3): 625-631.
24. Charalambous A, Giannakopoulou M, Bozas E, Paikousis L (2015) A randomized controlled trial for the effectiveness of progressive muscle relaxation and guided imagery as anxiety reducing interventions in breast and prostate patients undergoing chemotherapy. J Evid Based Complementary Altern Med 1-10.

25. Eyles C, Leydon GM, Hoffman CJ et al. (2015) Mindfulness for the self-management of fatigue, anxiety, and depression in women with metastatic breast cancer: a mixed methods feasibility study. Integr Cancer Ther 14(1): 42-56.

26. Leon Pizarro C, Gich I, Barth E et al. (2007) A randomized trial of the effect of training in relaxation and guided imagery techniques in improving psychological and quality-of-life indices for gynecologic and breast brachytherapy patients. Psycho-Oncology 16(11): 971-979.

27. Huebner J, Muenstedt K, Prott FJ et al. (2014) Online survey of patients with breast cancer on complementary and alternative medicine. Breast Care 9(1): 60-63.

28. Bradt J, Dileo C, Shim M (2013) Music interventions for preoperative anxiety. Cochrane Database Syst Rev 6(6): 1-81.

29. Pittman S, Kridli S (2011) Music intervention and preoperative anxiety: an integrative review. Int Nurs Rev 58(2): 157-163.

30. Nilsson U (2008) The anxiety- and pain-reducing effects of music interventions: a systematic review. AORN J 87(4):780-807.

31. Bae H, Bae H, Byung M, Cho S (2014) Effect of acupuncture in reducing preoperative anxiety: a meta-analysis. J Evid Based Complementary Altern Med 1-12.

32. Kwekkeboom K, Gretarsdottir E (2006) Systematic review of relaxation interventions for pain. J Nurs Scholarsh 38(3): 269-277.

33. Stoelting RK, Hillier SC (2006) Benzodiazepines. In: Brown B, Murphy F (Eds.), Pharmacology \& Physiology in Anesthetic Practice, $4^{\text {th }}$ (edn.), Philadelphia, PA: Lippincott Williams \& Wilkins, USA, pp. 140-154.

34. Sears SR, Bolton S, Bell KL (2013) Evaluation of "Step to Surgical Success" STEPS: A holistic perioperative medicine program to manage pain and anxiety related to surgery. Holist Nurs Prac 27(6): 349-357.

35. Bagheri-Nesami M, Mohseni-Bandpei MA, Shayesteh-Azar M (2006) The effect of the Benson Relaxation Technique on rheumatoid arthritis patients: extended report. Int J Nurs Prac12(4): 214-219.

36. Catarina de Arujo Elias A, Giglio JS, Andruciolli de Mattos Pimenta C, ElDash LG(2006)Therapeutical intervention, Relaxation, Mental images, and Spirituality (RIME) for spiritual pain in terminal patients. Sci World J 6: 2158-2169.

37. Hoffman CJ, Ersser SJ, Hopkinson JB, Nicholls PG, Harrington JE et al. (2012) Effectiveness of mindfulness-based stress reduction in mood, breast- and endocrine-related quality of life, and wellbeing in stage 0-III breast cancer: A randomized trial. J Clin Oncol 30(12): 1335-1342.

38. Acar HV, Cuvas O, Ceyhan A, Dikmen B (2012)Acupuncture on Yintang point decreases preoperative anxiety. J Altern Complement Med 19(5): 420-424.

39. Hernandez Palazon J, Fuentes-Garcia D, Falcon-Arana L, Rodriguez-Ribo A, Garcia-Palenciano C et al. (2015) Visual Analogue Scale for anxiety and Amsterdam Anxiety Scale provide a simple and reliable measurement of preoperative anxiety in patients undergoing cardiac surgery. Int Cardiovasc Res J 9(1): 1-6.

40. Moorey S, Greer S, Watson M, Gorman C, Rowden L, et al. (1991) The factor structure and factor stability of the hospital anxiety and depression scale in patients with cancer. Br J Psychiatry 158: 255-259.

41. Liberati A, Altman DG, Tetzlaff J, Cynthia Mulrow, Peter C Gøtzsche, et al. (2009) The PRISMA statement for reporting systematic reviews and meta-analysis of studies that evaluate healthcare interventions: explanation and elaboration. Br Med J: 339.

42. Garssen B, Boomsma MF, Meezenbroek E, Terry Porsild, Johannes Berkhof, et al. (2012) Stress management training for breast cancer surgery patients. Psycho-Oncology 22(3): 572-580.

43. Hsu S, Wang H, Chu S, Yen H (2010) Effectiveness of informational and emotional consultation on the psychological impact on women with 
breast cancer who underwent modified radical mastectomy. J Nurs Res 18(3): 215-224.

44. Palmer JB, Lane D, Mayo D, Schluchter M, Leeming R (2015) Effects of music therapy on anesthesia requirements and anxiety in women undergoing ambulatory breast surgery for cancer diagnosis and treatment: a randomized controlled trial. J Clin Oncol 33(28): 31623168.

45. Wysocki WM, Mitus J, Komorowski AL, Karolewski K (2012) Impact of preoperative information on anxiety and disease-related knowledge in women undergoing mastectomy for breast cancer: a randomized clinical trial. Acta Chir Belg 112(2): 111-115.

46. Brand LR, Munroe DJ, Gavin J (2013) The effect of hand massage on preoperative anxiety in ambulatory surgery patients. AORN J 97(6): 708-717.

47. Gonzalez EA, Ledesma RJ, McAllister DJ, Perry SM, Dyer CA, et al. (2012) Effects on guided imagery on postoperative outcomes in patients undergoing same-day surgical procedures: a randomized, single-blind study. AANA J 78(3): 181-188.

48. Cooke M, Chaboyer W, Schluter P, Hiratos MA (2005) The effect of music on preoperative anxiety in day surgery. J Adv Nurs 52(1): 47-55.

49. Arslan S, Ozer N, Ozyurt F (2008) Effect of music on preoperative anxiety in men undergoing urogenital surgery. Aust J Adv Nurs 26(2): 46-54.

50. Ai AL, Wink P, Shearer M (2012) Fatigue of survivors following cardiac surgery: Positive influences of preoperative prayer coping. Br J Healthy Psychol 17(4): 724-742.

51. Ko Y, Jen F (2012) The effect of using a relaxation tape on pulse, respiration, blood pressure and anxiety levels of surgical patients. J Clin Nurs 21(5-6): 689-697.
52. West AM, Bittner EA, Ortiz VE (2014) The effects of preoperative, videoassisted anesthesia education in Spanish on Spanish-speaking patients' anxiety, knowledge, and satisfaction: a pilot study. J Clin Anesth 26(4): 325-329.

53. Erci B, Sezgin S, Kacmaz Z (2008) The impact of therapeutic relationship on preoperative and postoperative patient anxiety. Aust J Adv Nurs 26(1): 59-66.

54. Ng S, Chau A, Leung WK (2004) The effect of preoperative information in relieving anxiety in oral surgery patients. Community Dent Oral Epidemiol 32(3): 227-235.

55. Stirling L (2006) Reduction and management of perioperative anxiety. Br J Nurs 15(7): 359-361.

56. Roykulcharoen V, Good M (2004) Systematic relaxation to reduce postoperative pain. J Adv Nurs 48(2): 140-148.

57. Seers K, Crichton N, Tutton L, Smith L, Saunders T (2008) Effectiveness of relaxation for postoperative pain and anxiety: randomized controlled trial. J Adv Nurs 62(6): 681-688.

58. Ni C, Tsai W, Lee L, Kao C, Chen Y (2012) Minimising preoperative anxiety with music for day surgical patients - a randomised clinical trial. J Clin Nurs 21(5-6): 620-625.

59. Bernatzky G, Presch M, Anderson M, Panksepp J (2011) Emotional foundations of music as a non-pharmacological pain management tool in modern medicine. Neurosci and Biobehav Rev 35(9): 1989-1999.

60. Ko Y, Lin P (2012) The effect of using a relaxation tape on pulse, respiration, blood pressure and anxiety levels of surgical patients. J Clin Nurs 21(5-6): 689-697.

61. Halpin LS, Speir AM, CapoBianco P, Barnett SD (2012) Guided imagery in cardiac surgery. Outcomes Manag 6(3): 132-137. 